\title{
Research of heat and mass transfer processes in conditions of microwave heating of wet wood
}

\author{
Anastasya A. Kostoreva ${ }^{1}$, Zhanna A. Kostoreva ${ }^{1}$, Lidiya V. Rogovaya ${ }^{1}$, and Vladimir S. \\ Loginov ${ }^{1, *}$ \\ ${ }^{1}$ National Research Tomsk Polytechnic University, 634050 Tomsk, Russia
}

\begin{abstract}
The results of experimental and theoretical studies of the processes of heat and mass transfer occurring during drying of wood under microwave heating are presented. The times of moisture removal are set. It is established that the dynamics of dehydration depends on the type of wood. Based on the results of experimental studies, a mathematical model of the heat transfer processes taking place under conditions of intensive phase transformations (evaporation of water) is formulated together during the dehydration of the wood. A comparative analysis of the theoretical and experimental values of the drying times showed their satisfactory consistency.
\end{abstract}

\section{Introduction}

Woodworking is one of the promising industries both in the Russian Federation and abroad. This is due in many respects to the geographical position of the country, the area of forests and their ability to self-renew. In recent years, the growth of the woodworking industry has begun in Russia, which requires blanks from coniferous and hardwood species. Such industries need high-quality processed products [1]. Therefore, wood is one of the most popular materials at the present time [2].

The growth of national economies is forcing the introduction of high technologies in the industry to meet the rapidly changing demands of consumers for wood products. The latter must be fulfilled as soon as possible [3].

As a rule, wet wood is brought to the production process that has not undergone preliminary processing (trimming bark, sawing, drying, etc.). At the same time, the finished products must be dry, because products made from raw wood, over time, change their properties (strength, shape, density, etc.). The main stage of wood processing is the removal of moisture. The drying process is one of the most energy-intensive processes in the woodworking industry, significantly increasing the cost of the final product by $20-30 \%$. This is due to the high duration of the process and large losses to the environment (infiltration through the openings of the outer walls of the chamber) [4]. One of the most promising technological solutions at the present time is the drying of wood in the field of microwave radiation (microwave drying). However, to date, the technology of microwave drying has not received sufficient propagation in industry due to the lack of elaboration of

\footnotetext{
* Corresponding author: $\underline{\text { loginovvs@tpu.ru }}$
} 
the physical theory of moisture removal in the microwave heating of wood. Full-scale research (experiment) of heat and mass transfer processes occurring during microwave drying of wood is very expensive and complex, and sometimes it is simply impossible. This is due to the numerous group of factors (type of wood, size of billet, type of sawing, etc.) [5]. Accordingly, it is necessary to exclude a large number of expensive and long-term field experiments [6]. Therefore, we can say that the use of the apparatus of mathematical modeling. However, the mathematical models developed at the present time are based on a number of significant assumptions that do not take into account the entire complex of thermophysical and electrophysical processes. So, for example, in [7], the results of mathematical modeling of microwave heating of a dielectric are presented, it is assumed that the distribution of the electric field vector over the sample is uniform, respectively, and the volume heat release is also unevenly distributed. However, as is well known from the works of Maxwell [8], the distribution of the electric field strength in space is not substantially uniform. In [9], the results of a numerical solution of the problem of heating a wood sample in a microwave field are presented, taking into account the nonuniformity of the EM field. However, this does not solve the problem of drying the samples. It is known [10] that when dehydrating porous materials a phase transition front separating the watersaturated and dry layers of wood is formed. Due to internal heating, it is possible to form an area of dehydrated wood inside the sample. These are multi-front tasks of drying. The latter are some of the most complex in mathematical physics.

Summarizing, it can be said that the development of an "adequate" physical theory and the mathematical basis for the microwave drying of wood that provides it is an urgent and unresolved task to date. The latter will contribute to the development of optimal drying modes for wet wood.

Objective: Experimental and theoretical investigation of the processes of heat and mass transfer proceeding together under conditions of intense phase (evaporation of water) transformations with intense convective-microwave heating of moist wood.

\section{Experiment}

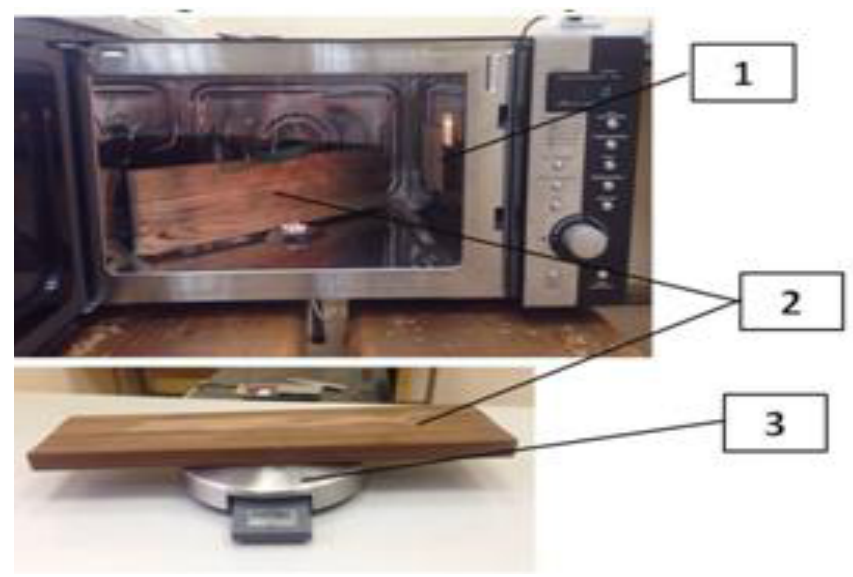

Fig. 1. Experimental setup: 1 - microwave oven, 2 - wood sample, 3 - scales.

Before the experiments, the wood blanks were brought to the moisture content $\varphi$ of the freshly cut tree $\varphi=30-40 \%$. After that, the samples were placed inside the microwave drying chamber. Then, the wood was removed and the control weighing was carried out (the holding time of the wet billet in the microwave oven was 60 seconds, the weighing period was not more than $0.1 \cdot \mathrm{t}_{\mathrm{dry}}$ ). After weighing, the blank was again placed inside the 
microwave chamber and further heating was carried out. The experiments were repeated until the humidity change in the wood in 60 seconds did not exceed $0.01 \%$.

\section{Formulation of the problem}

Based on the results of the experiments, the physical and mathematical models of the investigated process are formulated.

Physical setting

At the initial time $(\tau=0)$, the wood preform enters the drying chamber and is heated by the combined action of microwave radiation. As a result of microwave exposure, internal heat generation occurs and the evaporation of moisture is initiated. Accordingly, a layer of dry wood with a low coefficient of thermal conductivity is formed inside the wood sample. The time interval from the beginning of heating to the moment of hollow drying (complete removal of moisture) is considered the drying time $t$.

Accordingly, it is possible to form a dry layer within the sample and the appearance of a second evaporation front that moves from the depth of the workpiece to the surface.

Mathematical statement

Mathematically, the drying process within the framework of the formulation corresponding to the above physical model is described by the energy equation for wet wood, taking into account the endothermic evaporation effect:

$$
c(\mathrm{~T}) \rho(\mathrm{T}) \frac{\partial T}{\partial \tau}=\frac{\partial}{\partial x}\left(\lambda \frac{\partial T}{\partial x}\right)-\frac{Q_{e v a} \cdot W_{e v a} \cdot \delta\left(x_{v}\right)}{h_{d}}+q_{U H F} \cdot \theta\left(x_{\text {eva }}-x\right)
$$

$\mathrm{W}_{\text {eva }}$ - the evaporation rate $\left(\mathrm{kg} /\left(\mathrm{m}^{2} \cdot \mathrm{s}\right)\right)$ have been calculated according to the formula [11]:

$$
W_{\text {eva }}=\frac{\mathrm{V}_{0} \cdot \exp \left[-\mathrm{Q}_{\text {eva }} \cdot \mu_{0} \cdot(\mathrm{T}-273)\right]}{\mathrm{R} \cdot \mathrm{T} \cdot 273}
$$

$\mathrm{q}_{\mathrm{uhf}}$ - thermal effect $\left(\mathrm{W} / \mathrm{m}^{3}\right) \mathrm{UHF}$ impact:

$$
q_{U H F}=\varepsilon 1 \cdot f \cdot \operatorname{tg} \delta \cdot|E|^{2}
$$

where: c - heat capacity, $\mathrm{j} /(\mathrm{kg} \cdot \mathrm{K}) ; \rho$ - density, $\mathrm{kg} / \mathrm{m}^{3} ; \lambda$ - thermal conductivity, $\mathrm{W} /(\mathrm{m} \cdot \mathrm{K}) ; \mathrm{T}$ - temperature, $\mathrm{K} ; \theta-$ the Heaviside function; $\delta$ - a discrete function of Dirk; $Q_{\text {eva }}$ - heat of the endothermic effect of evaporation, $\mathrm{j} / \mathrm{kg} ; \mathrm{h}_{\mathrm{d}}$ — ratio to smearing of the evaporation front, $\mathrm{m} ; \varepsilon_{1}$ - the dielectric penetrability; $\mathrm{f}$ - frequency of electromagnetic field, $\mathrm{Hz} ; \operatorname{tg} \delta$ - the angle; $\left|E^{2}\right|-$ the potential stress of the electromagnetic field, $\mathrm{V} / \mathrm{m}, \mu_{0}$ — the molar mass of water, $\mathrm{kg} / \mathrm{mol}$.

- equation (1) has been solved under the following boundary conditions:

$$
\begin{gathered}
\tau=0: T=T_{0} \\
x=0: \frac{\partial T}{\partial x}=0 ;
\end{gathered}
$$




$$
x=l: \lambda \frac{\partial T}{\partial x}=\alpha\left(\mathrm{T}_{e}-\mathrm{T}\right)
$$

The problem (1) - (5) was solved by the method of finite differences using the algorithm similarly to [12]. The rate of "dehydration" was calculated by the method of implicit separation of the evaporation front [13].

\section{The results}

Table 1 shows the experimentally and theoretically obtained drying times for wood. It can be noted that the times of complete drying of the wood sample from the cedar practically coincide. But for the spruce specimen, the deviation of the theoretical and experimental drying times is about $30 \%$. The latter can be explained by the fact that the initial data used in mathematical modeling of the thermophysical and electrophysical characteristics of spruce sith differ from the analogous parameters of the common spruce used in the experiment.

Table 1. Experimental and theoretical times of wood drying.

\begin{tabular}{|c|c|c|c|}
\hline $\begin{array}{c}\text { Type of } \\
\text { wood }\end{array}$ & $\begin{array}{c}\mathrm{t}_{\text {dry }}, \mathrm{s} . \\
\text { Theoretica } \\
1 \text { values. }\end{array}$ & $\begin{array}{c}\mathrm{t}_{\text {dry }}, \mathrm{s} . \\
\text { Experiment } \\
\text { al values. }\end{array}$ & $\begin{array}{c}\text { Relative } \\
\text { deviation } \\
\text { of drying } \\
\text { times\% }\end{array}$ \\
\hline fir & 568 & 645 & 11.94 \\
\hline spruce & 564 & 810 & 29.13 \\
\hline pine & 579 & 510 & 13.53 \\
\hline cedar & 560 & 660 & 1.52 \\
\hline
\end{tabular}

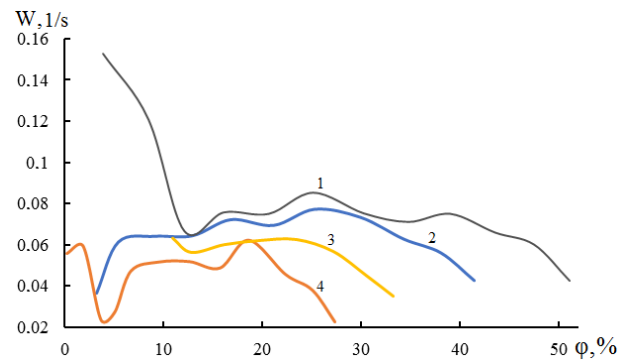

Fig. 2. Dependence of the relative rate of moisture removal $\mathrm{W}=\Delta \varphi / \mathrm{s}$ on absolute humidity $\varphi$ for samples made of wood: 1 - spruce; 2 - fir; 3 - pine; 4 - cedar.

Figure 2 shows the dependence of the moisture removal rates on absolute humidity for samples made from different types of wood. It can be noted that the longest dehydration period corresponds to the drying of spruce, while the lowest rate of moisture removal is recorded in cedar. This is due to the significant differences in the thermal and electrical properties of wood. The shape of the W $(\varphi)$ curves for all types of wood is the same, however, for the samples from spruce and cedar in the final stage (for spruce $\tau=720$ seconds, for cedar $\tau=630$ seconds) drying, the dewatering rates increase abruptly.

Figure 3 shows the dependence of the absolute humidity change $\varphi$ on time for samples made from different types of wood. It is possible to note the absolutely identical character of the curves. Accordingly, it can be said that the mechanism of moisture removal for all investigated samples of wood is the same. It can also be noted that the curves $\varphi(t)$ are practically linear. Accordingly, it can be assumed that the drying process can be described by simple polynomial expressions.

Figure 4 shows the dependence of the change in the mass of the wood billet on the drying time for samples made from different types of wood. The characteristics of the change in the mass of the bar for spruce and cedar are almost identical, accordingly, it can be reasonably concluded that such types of wood can be dried in one drying chamber. The dehydration characteristics of fir significantly differ from those of pine, spruce and cedar. Accordingly, wood samples made of fir, it is necessary to dry separately from the rest. 


\section{Conclusion}

The results of experimental and numerical studies of the processes of heat and mass transfer

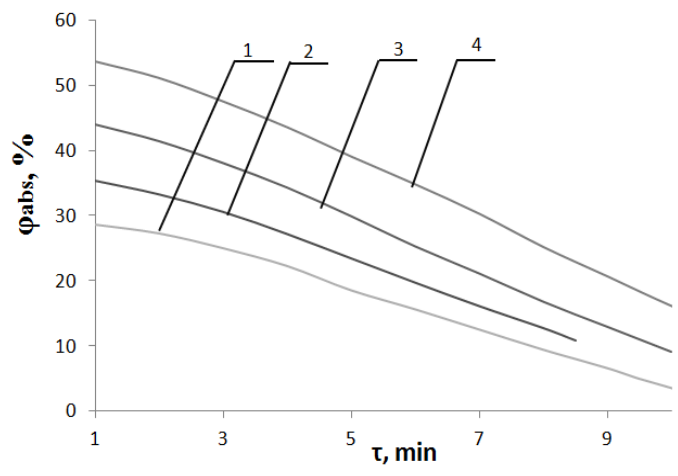

Fig. 3. Dependence of absolute humidity $\varphi_{\text {abs }}$ from the drying time $\tau$ for samples made of wood:

1 - cedar; 2 - pine; 3 - fir; 4 - spruce.

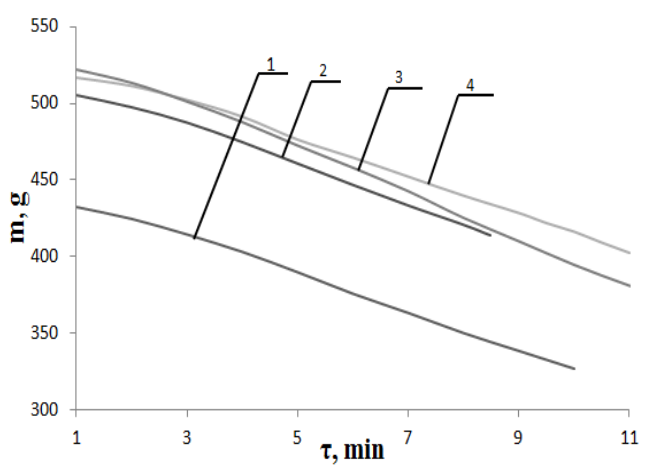

Fig. 4. Dependences of the change in sample mass (m) from the drying time $\tau$ for samples made of wood: 1 - fir; 2 - pine; 3 - tree; 4 - cedar.

in the conditions of microwave heating of moist wood are presented. Based on the results of the experimental study, the rate of moisture removal from the absolute moisture content of the wood sample was found to be significant, and it was noted that this dependence is essentially nonlinear. So in the initial drying period, the rate of moisture removal increases, however, after the time $\tau=0.74 \cdot \tau$ drying, the dehydration rate begins to decrease. A comparative analysis of the experimental data obtained and the theoretical dependences shown showed satisfactory agreement. Based on the results of experimental studies, a mathematical model was developed for the processes of heat and mass transfer occurring during microwave drying. According to the results of mathematical modeling, it was found that the integral characteristics of the drying process depend substantially on the type of wood. For example, the time for drying pine, spruce and cedar is approximately the same, while tusch fir is significantly different. Accordingly, it can be concluded that wood blanks of pine, spruce and cedar can be dewatered simultaneously in one drying chamber.

\section{References}

1. R.R. Safin, J. of Tomsk State University 11, 4 (2006)

2. O.A. Kizina, A.L. Adamovich, J. of Polotsk State University 3, (2011).

3. Yu.G. Grazenberg, A.L. Adamovich, Yu.V. Matieniuk, J. of Polotsk State University. 3, 114 (2012)

4. A.I. Raseev, Drying of wood, (EDP Lan', St. Petersburg, 2014)

5. G.A. Morozov, Antennas release 1, 40 (1998)

6. G.V. Kuznetsov, M.A. Sheremet, Difference methods for solving heat conduction problems (Publishing house TPU, Tomsk, 2007). 
7. V.V. Salomatov, S.O. Sladkov, S.E. Pashchenko, J. Eng. Phys. Thermophys. 85, 3 (2012)

8. J.C. Maxwell, Phil. Trans. R. Soc. Lond. 155, (1865)

9. F. Erchiqui, Z. Annasabi, M. Souli, F. Slaoui-Hasnaoui. 3D numerical analysis of the thermal effect and dielectric anisotropy on thawing frozen wood using microwave energy. Int. J. of Thermal Sciences 89, (2015)

10. A.V. Lykov, Theory of drying, (Energia, Moscow, 1968)

11.A.A. Khashchenko, O.V. Vecher, E.I. Diskkaeva, J. of Altai State University. 1, 89 (2016)

12.S.V. Syrodoy, N.Yu. Gutareva, R.I. Taburchinov. MATEC Web of Conferences 72, 01109 (2016)

13. Syrodoy S.V., Gutareva N.Y., Bugaeva K. A. MATEC Web of Conferences 72, 01035 (2016) 